\title{
Preparation and Characterization of Transdermal Therapeutic System Containing Simvastatin: A Statistical Study
}

\author{
Santosh Kumar Mishra', Rahul Kumar², Purushottam Ramchandra Patil ${ }^{3}$, Rishiksh Gupta ${ }^{4}$, \\ Alok Mahor ${ }^{4}$, Peeyush Bhardwaj ${ }^{4, *}$ \\ ${ }^{1}$ Institute of Technology and Management, GIDA, Gorakhpur, Uttar Pradesh, INDIA. \\ ${ }^{2}$ Shobhit Institute of Engineering and Technology (Deemed to be University), School of Pharmaceutical Science, Meerut, \\ Uttar Pradesh, INDIA. \\ ${ }^{3}$ Government College of Pharmacy, Osmanpura, Aurangabad, Maharashtra, INDIA. \\ ${ }^{4}$ Institute of Pharmacy, Bundelkhand University, Jhansi, Uttar Pradesh, INDIA.
}

\begin{abstract}
Introduction: The purpose of the present study was to design, develop, and characterize the transdermal patches containing Simvastatin for the management of blood lipid levels. Materials and Methods: Transdermal patches of Simvastatin were prepared by the solvent casting method. The prepared patches were evaluated for physicochemical characteristics such as thickness, weight variation, folding endurance, percentage moisture uptake, percentage moisture content, percentage drug content, and ex-vivo permeation study. Eudragit polymer grades ERL100 and ERS100 were used in 6:4 and 8:2 ratio to prepare the formulations. Formulations were prepared using $2^{3}$ factorial designs. Stability studies of the films were subjected to the environmental conditions at a temperature of $45^{\circ} \mathrm{C}$, $75 \%$ relative humidity for 45 days. Results: The permeation parameters like flux, amount of drug permeated, and permeability coefficient were obtained. It was found that all these values were highest for formulation F8. Conclusion: Based on all parameters, formulation F8 was considered as the best formulation.
\end{abstract}

Key words: Transdermal patches, Simvastatin, Factorial designs, Matrix, Eudragit.

\section{INTRODUCTION}

The topical route of drugs has some limitations, so if not properly designed they have only local therapeutic effects. Transdermal patches containing drugs are the unique form of delivery of drugs for the entire surface of the skin. Skin is the largest organ of the body having a large surface area. It contains several layers and ultimately capillaries found just below the skin. Transdermal drug delivery has many advantages over drugs for oral route and parenteral. In drug toxicity and overdose, drugs can be easily withdrawn from the application site. Transdermal is the route which follows fully hepatic bypassing and hence reduces the degradation by hepatic enzymes. Another advantage associated with this is convenient to use appropriate for many hours or days. Such a type of useful dosage form usually increases patient compliances. ${ }^{1}$ Transdermal drug delivery systems are applied on the skin that may deliver the medicament into the circulatory system of the body at a predefined rate. A transdermal drug delivery system is a different delivery system than the oral or parenteral drug delivery systems. In this system, the drug enters into the circulation directly via the skin by the diffusion process. A high concentration gradient of the drugs in a patch facilitates proper diffusion into the blood circulation. This maintains a constant and appropriate concentration of drug in the blood flow. ${ }^{2}$

Simvastatin is the drug used in the delivery system. It is an oral antilipemic agent
Submission Date: 06-08-2020; Revision Date: 19-12-2020; Accepted Date: 28-07-2021.

DOI: 10.5530/ijper.56.1.14 Correspondence: Dr. Peeyush Bhardwaj, Associate Professor, Institute of Pharmacy, Bundelhand University, Jhansi, Uttar Pradesh, INDIA. E-mail:meet2peeyush@ gmail.com

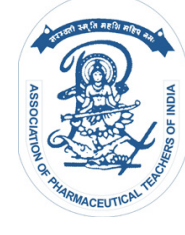

www.ijper.org 
which inhibits HMG-CoA reductase. It is used in the treatment of primary hypercholesterolemia and is effective in reducing total and LDL-cholesterol, plasma triglycerides, and apolipoprotein B.

\section{MATERIALS AND METHODS}

\section{Materials}

The drug was collected from Cadila Pharma. Ltd., Gujarat as a gift sample. All grades of Eudragit were obtained from Evonik Industries, Germany as a gift sample. Other chemicals and polymers collected were of analytical grades.

\section{Methods}

\section{Formulation of Transdermal Patches}

Transdermal patches were prepared by the solvent casting technique employing a mercury substrate. Eudragit ERL100 and ERS100 in different ratiosusing $2^{3}$ factorial designs were used to prepare matrix-type transdermal patch as given in Tables 1 and 2. Simvastatin was taken as a drug in each formulation and dibutyl phthalate was used as plasticizer ${ }^{3}$ in the two different ratios. DMSO (dimethyl sulphoxide) was used as a penetration enhancer in the formulations. A total of eight formulations were prepared and studied. After $24 \mathrm{hr}$ the patches were cut into the required size. The composition of various patches was taken according to the 2-level factorial design. The desiccator is used for storing transdermal patches.

\begin{tabular}{|c|c|c|}
\hline \multicolumn{2}{|c|}{ Table 1: Independent variables and levels. } \\
\hline \multirow{2}{*}{ Independent Variable } & \multicolumn{2}{|c|}{ Level } \\
\cline { 2 - 3 } & Low (-1) & High(+1) \\
\hline A(Polymer-ERL100:ERS100) & $6: 4$ & $8: 2$ \\
\hline B(Plasticizer \%w/w) & 30 & 40 \\
\hline C(Penetration enhancer \%w/w) & 0.25 & 0.50 \\
\hline
\end{tabular}

\begin{tabular}{|c|c|c|c|c|}
\hline \multicolumn{5}{|c|}{ Table 2: 2- Level Factorial Design. } \\
\hline Std & Run & $\begin{array}{c}\text { Fac. 1 } \\
\text { polymer } \\
\text { conc. }\end{array}$ & $\begin{array}{c}\text { Fac. 2 } \\
\text { plasticizer } \\
\text { conc. }\end{array}$ & $\begin{array}{c}\text { Fac.3 } \\
\text { penetration } \\
\text { Enhancer }\end{array}$ \\
\hline 3 & 1 & -1.00 & 1.00 & -1.00 \\
\hline 2 & 2 & 1.00 & -1.00 & -1.00 \\
\hline 7 & 3 & -1.00 & 1.00 & 1.00 \\
\hline 4 & 4 & 1.00 & 1.00 & -1.00 \\
\hline 1 & 5 & -1.00 & -1.00 & -1.00 \\
\hline 5 & 6 & -1.00 & -1.00 & 1.00 \\
\hline 8 & 7 & 1.00 & 1.00 & 1.00 \\
\hline 6 & 8 & 1.00 & -1.00 & 1.00 \\
\hline
\end{tabular}

Evaluation of physicochemical properties of Transdermal Patches

\section{Thickness}

The thicknesses of transdermal patches were determined by digital Vernier calipers of least count $0.001 \mathrm{~mm}$ at different points and the average of all was computed.

\section{Folding endurance}

Folding endurance is the capability or strength of patches to withstand repeated folding at a single point. It is obtained as a maximum number of counts of folding of patches to retain its breakability. ${ }^{4,5}$

\section{Uniformity of weight}

Weight variation was obtained by weighing 20 sample patches and the average weight of the sample was then calculated. The insignificant deviation from average weight is the uniformity of weight. ${ }^{4,5}$

\section{Percentage moisture content}

The sample of prepared films was initially weighed properly and kept in a desiccator containing partially filled with calcium chloride at the base and kept for $24 \mathrm{~h}$ at room temperature. The fillms were weighed and the percentage moisture content was obtained as a ratio of a difference value between initial and final weight to final weight multiplied by $100 .^{6,8}$

$$
\% \text { moisture content }=\frac{\begin{array}{l}
\text { initial weight }- \\
\text { final weight }
\end{array}}{\text { initial weight }} \times 100
$$

\section{Percentage moisture uptake}

Previously weighed patches were stored in a desiccator containing a saturated solution of potassium chloride to provide $80 \% \mathrm{RH}$ for $24 \mathrm{~h}$ at room temperature. The percentage of moisture uptake was calculated as the ratio of a difference value between final and initial weight to initial weight multiplied by 100 .

$$
\begin{aligned}
& \text { final weight - } \\
& \% \text { moisture uptake }=\frac{\text { initial weight }}{\text { initial weight }} \times 100
\end{aligned}
$$

\section{Drug content determination}

Ten patches were weighed separately and dissolved in $100 \mathrm{ml}$ of methanol. The solution was filtered through a $0.45 \mu \mathrm{m}$ filter before drug analysis. The drug content was estimated spectrophotometrically at $\lambda_{\text {max }}$ of $238.9 \mathrm{~nm}$. 


\section{Ex-vivo evaluation of transdermal patches}

\section{Permeation studies acrosshuman cadaver skin ${ }^{6}$}

\section{Preparation of human cadaver skin}

Human cadaver skin obtained from Lala Lajpat Rai Medical College, Meerut, was dermatomed carefully and was washed with deionized water. The skin was then treated with a 5\%w/v solution of EDTA (ethylene diamine tetra acetic acid) for $8 \mathrm{hr}$. The epidermis was removed from the dermis carefully with forceps. The epidermal side of the skin was again washed with deionized water and was spread over cellophane. The storage of the skin was done in a freezer until used. In the experiment, the skin was collected and soaked in a phosphate buffer solution for $1 \mathrm{hr}$. It was gently dried by blotting over filter paper. Before using the skin sample was examined with a microscope for any histological changes.

Simvastatin release from the patch was measured through human cadaver skin using a diffusion cell. The area of diffusion cell was $1.75 \mathrm{~cm}^{2}$ and the volume of the receptor compartment was $25 \mathrm{ml}$. The treated human cadaver skin was placed between the donor and receptor compartment. Simvastatin loaded patch with area $1 \mathrm{~cm}^{2}$ was placed on the membrane surface which was sealed from the atmosphere with paraffin. The solution was filled as such in the receptor compartment to touch the dermal side of the skin. A magnetic stirrer was used for stirring the solution in the receptor compartment using a magnetic bead. During the experiment, the solution in the receptor side was kept at $37 \pm 1^{\circ} \mathrm{C}$ temperature. At different time intervals, the samples were withdrawn from the diffusion cell by using a pipette for up to $24 \mathrm{hr}$. The collected samples were analyzed for the drug permeated across the skin. Receptor volume was adjusted with an equal volume of buffer at each time interval., ${ }^{9,10}$ The observations are listed in Table 3.

\section{Stability Studies}

Formulations were studied for stability studies. These selected formulations were studied for different parameters for 45 days. The storage temperature and relative humidity were kept at $40 \pm 2^{\circ} \mathrm{C}$ and $75 \pm 5 \%$ respectively. ${ }^{11,12}$

\section{RESULTS}

Analysis of variance table with design summary of the obtained results are given in Table 4. Observations of the thickness of transdermal patches were given in Table 5. To evaluate the thickness of different transdermal patches, ANOVA for the selected factorial model was done and details are given in Table 6 and Figure 2. The Bar-graph of the thickness of the formulations is given in Figure 1.

The mathematical models eliciting the effects of the various factors and their interactions over the thickness of patches were:

Thickness $=153.38+4.37 \quad \mathrm{~A}+5.87 \quad \mathrm{~B}+5.62 \quad \mathrm{C}-1.12 \quad \mathrm{~A}$ B+1.63 A C+1.13 BC-0.88 A B C

Where, $\mathrm{A}=$ Polymer, $\mathrm{B}=$ Plasticizer, and $\mathrm{C}=$ Penetration enhancer.

Different folding endurance values of transdermal patches were given in Table 5 To evaluate the folding endurance, ANOVA for the selected factorial model

\begin{tabular}{|c|c|c|c|c|c|c|c|c|}
\hline \multicolumn{7}{|c|}{ Table 3: Percent drug permeate from simvastatin patches across human cadaver skin. } \\
\hline Time (hr) & \multicolumn{7}{|c|}{ Percent drug permeated ${ }^{*}$} \\
\hline & $\mathbf{F}_{1}$ & $\mathbf{F}_{2}$ & $\mathbf{F}_{3}$ & $\mathbf{F}_{4}$ & $\mathbf{F}_{5}$ & $\mathbf{F}_{6}$ & $\mathbf{F}_{7}$ & $\mathbf{F}_{8}$ \\
\hline 1 & $6.44 \pm 0.24$ & $5.45 \pm 0.18$ & $5.83 \pm 0.126$ & $5.85 \pm 0.283$ & $6.02 \pm 0.314$ & $5.69 \pm 0.2445$ & $5.6 \pm 0.168$ & $6.00 \pm 0.323$ \\
\hline 2 & $10.3 \pm 0.36$ & $9.95 \pm 0.30$ & $10.2 \pm 0.296$ & $10.2 \pm 0.335$ & $10.9 \pm 0.388$ & $10.0 \pm 0.3156$ & $10.3 \pm 0.258$ & $10.8 \pm 0.463$ \\
\hline 3 & $13.3 \pm 0.42$ & $12.8 \pm 0.45$ & $13.9 \pm 0.325$ & $11.9 \pm 0.532$ & $14.1 \pm 0.613$ & $13.5 \pm 0.462$ & $14.9 \pm 0.39$ & $14.3 \pm 0.686$ \\
\hline 4 & $151.4 \pm 0.60$ & $17.9 \pm 0.56$ & $16.6 \pm 0.432$ & $16.8 \pm 0.724$ & $17.7 \pm 0.695$ & $16.8 \pm 0.677$ & $17.6 \pm 0.467$ & $17.6 \pm 0.754$ \\
\hline 5 & $16.7 \pm 0.68$ & $22.1 \pm 0.76$ & $21.2 \pm 0.58$ & $21.1 \pm 0.651$ & $20.6 \pm 0.735$ & $20.3 \pm 0.585$ & $20.5 \pm 0.459$ & $20.2 \pm 0.708$ \\
\hline 6 & $23.2 \pm 0.73$ & $26.7 \pm 0.83$ & $26.8 \pm 0.655$ & $25.8 \pm 0.845$ & $25.6 \pm 0.792$ & $24.0 \pm 0.757$ & $24.2 \pm 0.647$ & $24.1 \pm 0.838$ \\
\hline 7 & $26.5 \pm 0.75$ & $29.8 \pm 0.80$ & $30.1 \pm 0.745$ & $29.1 \pm 0.882$ & $31.5 \pm 0.839$ & $28.8 \pm 0.783$ & $28.4 \pm 0.715$ & $27.8 \pm 0.873$ \\
\hline 8 & $30.4 \pm 0.87$ & $304.7 \pm 0.56$ & $33.2 \pm 0.783$ & $31.8 \pm 0.768$ & $34.6 \pm 0.812$ & $30.6 \pm 0.747$ & $32.0 \pm 0.688$ & $30.9 \pm 0.858$ \\
\hline 9 & $33.3 \pm 0.65$ & $33.04 \pm 0.78$ & $37.1 \pm 0.868$ & $35.5 \pm 0.802$ & $38.7 \pm 0.926$ & $33.4 \pm 0.583$ & $36.0 \pm 0.764$ & $33.8 \pm 0.802$ \\
\hline 10 & $35.5 \pm 0.82$ & $39.6 \pm 0.86$ & $40.8 \pm 0.983$ & $38.8 \pm 0.967$ & $40.9 \pm 0.783$ & $37.1 \pm 0.738$ & $38.9 \pm 0.887$ & $36.6 \pm 0.960$ \\
\hline 11 & $39.3 \pm 0.94$ & $43.04 \pm 0.82$ & $43.8 \pm 0.957$ & $41.9 \pm 0.945$ & $44.7 \pm 0.868$ & $41.2 \pm 0.955$ & $42.4 \pm 0.984$ & $40.5 \pm 1.057$ \\
\hline 12 & $43.8 \pm 1.24$ & $44.5 \pm 1.04$ & $45.1 \pm 1.19$ & $43.4 \pm 1.27$ & $46.0 \pm 0.985$ & $43.8 \pm 1.21$ & $46.1 \pm 1.06$ & $45.4 \pm 1.345$ \\
\hline 24 & $67.5 \pm 1.84$ & $70.1 \pm 2.14$ & $69.4 \pm 1.76$ & $68.08 \pm 2.45$ & $71.3 \pm 1.85$ & $67.7 \pm 2.37$ & $68.8 \pm 2.23$ & $70.7 \pm 2.54$ \\
\hline
\end{tabular}

* mean \pm S.D, $n=3$ 


\begin{tabular}{|c|c|c|c|c|c|c|c|c|}
\hline \multicolumn{10}{|c|}{ Table 4: Design summary. } \\
\hline Name & Units & Obs & Analysis & Minimum & Maximum & Mean & Std. Dev. & Ratio \\
\hline Thickness & $\mu \mathrm{m}$ & 8 & Factorial & 140 & 170 & 153.37 & 10.2112 & 1.21429 \\
\hline weight variation & $\mathrm{Mg}$ & 8 & Factorial & 24.5 & 26.8 & 25.65 & 0.84176 & 1.09388 \\
\hline folding endurance & - & 8 & Factorial & 102 & 221 & 165.75 & 46.6836 & 2.16667 \\
\hline moisture uptake & $\%$ & 8 & Factorial & 1.103 & 2.627 & 1.8328 & 0.50544 & 2.38169 \\
\hline moisture content & $\%$ & 8 & Factorial & 1.42 & 3.66 & 2.2025 & 0.67635 & 2.57746 \\
\hline Drug Content & $\%$ & 8 & Factorial & 85.45 & 95.68 & 91.52 & 3.2582 & 1.11972 \\
\hline Drug permeation & $\mu \mathrm{m} / \mathrm{cm}^{2}$ & 8 & Factorial & 595.2 & 680.3 & 634.63 & 33.5609 & 1.14298 \\
\hline
\end{tabular}

\begin{tabular}{|c|c|c|c|c|c|c|c|}
\hline \multicolumn{7}{|c|}{ Table 5: Physicochemical evaluation of different formulations. } \\
\hline $\begin{array}{c}\text { Formulation } \\
\text { code }\end{array}$ & $\begin{array}{c}\text { Thickness } \\
(\boldsymbol{\mu} \pm \text { SD) }\end{array}$ & $\begin{array}{c}\text { Folding } \\
\text { endurance }\end{array}$ & $\begin{array}{c}\text { Weight } \\
\text { variation } \\
(\mathbf{m g} \pm \text { SD) }\end{array}$ & $\begin{array}{c}\text { Moisture } \\
\text { uptake (\%) }\end{array}$ & $\begin{array}{c}\text { Moisture } \\
\text { content (\%) }\end{array}$ & $\begin{array}{c}\text { Drug content } \\
(\%)\end{array}$ & $\begin{array}{c}\text { Overall } \\
\text { desirability }\end{array}$ \\
\hline F1. & $144 \pm 14.28$ & $112.2 \pm 4.91$ & $25 \pm 1.469$ & $1.35 \pm 0.163$ & $1.83 \pm 0.089$ & $90.37 \pm 4.06$ & 0.354 \\
\hline F2. & $155 \pm 15.49$ & $195 \pm 7.738$ & $26.2 \pm 1.78$ & $1.46 \pm 0.199$ & $2.25 \pm 0.117$ & $92.82 \pm 5.33$ & 0.682 \\
\hline F3. & $150 \pm 10.77$ & $135 \pm 6.046$ & $25.1 \pm 1.41$ & $1.93 \pm 0.299$ & $1.74 \pm 0.166$ & $89.64 \pm 3.66$ & 0.000 \\
\hline F4. & $160 \pm 13.26$ & $201 \pm 6.679$ & $26.4 \pm 1.62$ & $2.11 \pm 0.136$ & $2.42 \pm 0.130$ & $94.42 \pm 5.11$ & 0.586 \\
\hline F5. & $162 \pm 15$ & $210 \pm 5.436$ & $26.2 \pm 1.09$ & $2.2 \pm 0.164$ & $2.32 \pm 0.139$ & $93.46 \pm 4.44$ & 0.574 \\
\hline F6. & $146 \pm 9.165$ & $150 \pm 4.928$ & $25 \pm 1.24$ & $1.89 \pm 0.179$ & $1.98 \pm 0.151$ & $90.32 \pm 2.85$ & 0.265 \\
\hline F7. & $140 \pm 6.403$ & $102 \pm 4.9$ & $24.5 \pm 1.07$ & $1.10 \pm 0.169$ & $1.42 \pm 0.137$ & $85.45 \pm 3.35$ & 0.000 \\
\hline F8. & $170 \pm 8.306$ & $221 \pm 5.585$ & $26.8 \pm 0.9$ & $2.62 \pm 0.195$ & $3.66 \pm 0.153$ & $95.68 \pm 4.68$ & 0.867 \\
\hline
\end{tabular}

\begin{tabular}{|c|c|c|c|c|c|}
\hline \multicolumn{6}{|c|}{ Table 6: Analysis of variance table [Partial sum of } \\
squares - Type III for thickness].
\end{tabular}

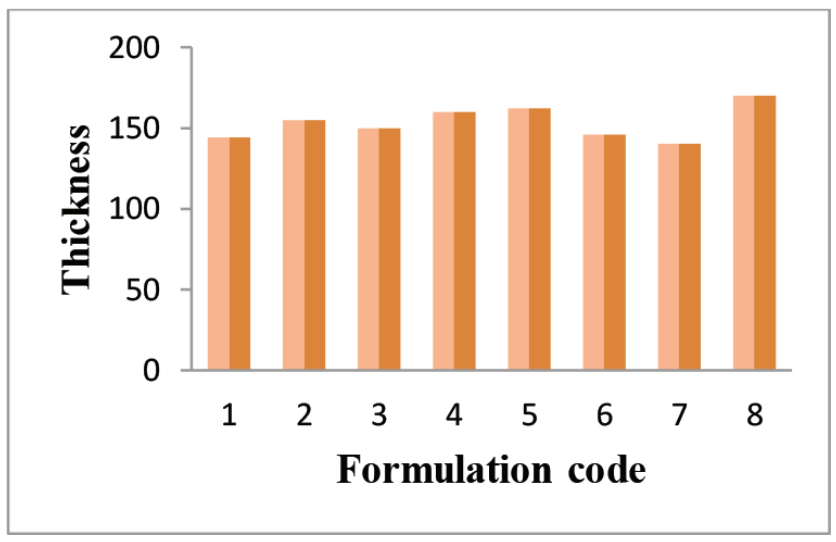

Figure 1: Thickness of different formulations.
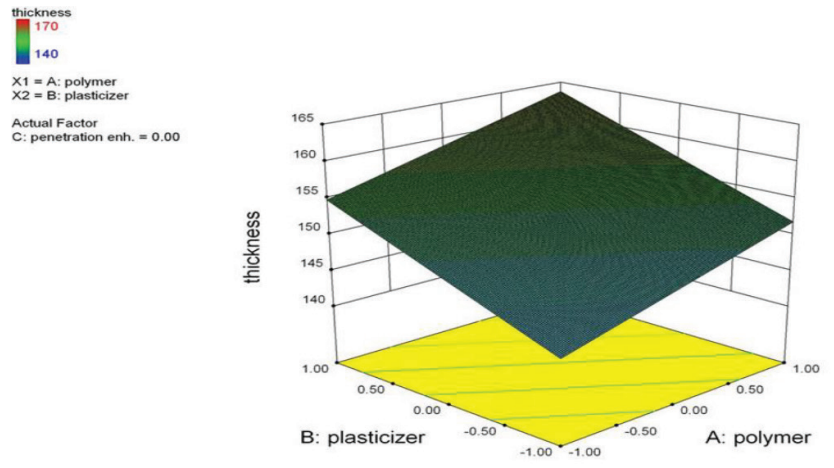

Figure 2: Thickness of patches as a function of: a) polymer, b) plasticizer.

was done and details are given in Figure 4 and graph of different formulations vs their respective folding endurance is given in Figure 3. The Bar-graph of folding endurance values of different formulations is reported in Figure 3.

Different weight variation observations of the patches were given in Table 5

To evaluate the weight variation of patches, ANOVA for the selected factorial model was done and details are given in Table 7 and Figure 6 and graph of different 


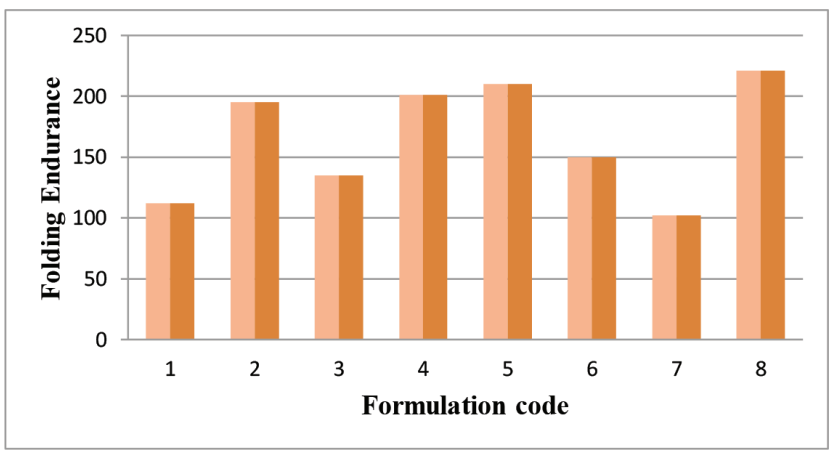

Figure 3: Folding endurance of different formulations.

\begin{tabular}{|c|c|c|c|c|c|}
\hline Source & $\begin{array}{l}\text { Sum of } \\
\text { Squares }\end{array}$ & $\mathrm{D}_{f}$ & $\begin{array}{l}\text { Mean } \\
\text { Square }\end{array}$ & $F$ Value & $\begin{array}{l}p \text {-value } \\
\text { Prob }>\text { F }\end{array}$ \\
\hline $\begin{array}{c}\text { Model } \\
\text { significant }\end{array}$ & 4.68 & 3 & 1.56 & 22.72 & 0.0057 \\
\hline A-polymer & 1.62 & 1 & 1.62 & 23.56 & 0.0083 \\
\hline B-plasticizer & 1.44 & 1 & 1.44 & 21.02 & 0.0101 \\
\hline $\begin{array}{c}\text { C-penetration } \\
\text { enhancer }\end{array}$ & 1.62 & 1 & 1.62 & 23.56 & 0.0083 \\
\hline
\end{tabular}
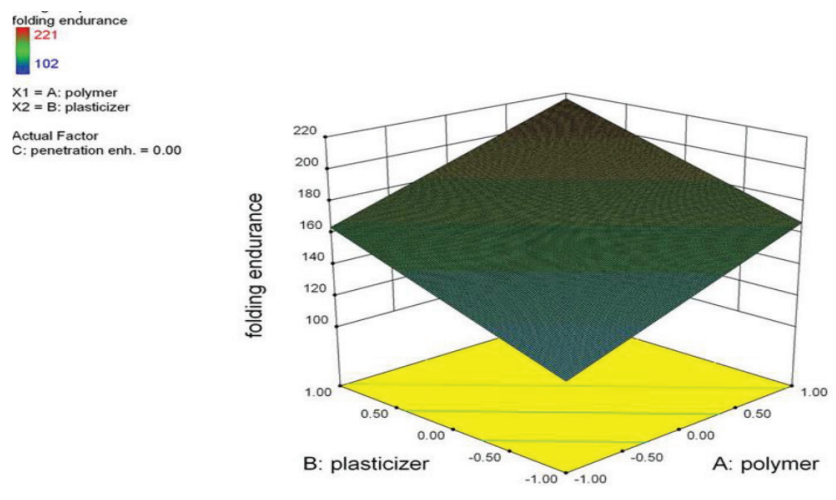

Figure 4: Folding endurance of patches as a function of a) polymer, b) plasticizer.

formulations vs their weight variations are given in Figure 5 . The bar-graph of the weight variation of the formulations is given in Figure 5.

Different percent moisture content values of transdermal patches were given in Table 5 . To evaluate the moisture content of patches, ANOVA for the selected factorial model was done and details are given in Table 8 and Figure 8. The bar-graph of different formulation vs their percent moisture content is given in Figure 7. The mathematical models eliciting the effects of the various factors and their interactions over percentage moisture content of patches were:

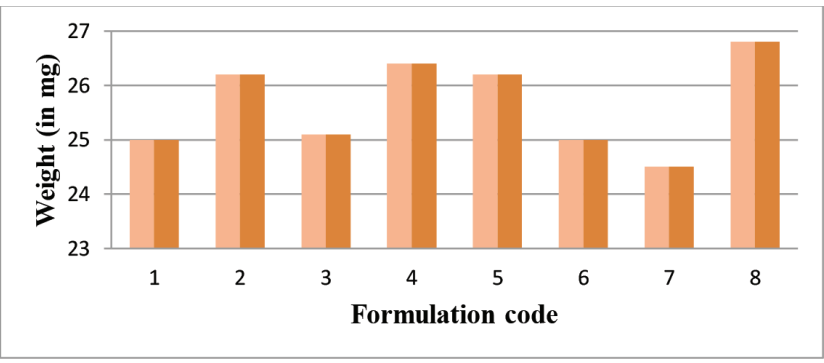

Figure 5: Weight variations of different formulations.

\section{Table 8: Analysis of variance table [Partial sum of squares - Type III for moisture content].}

\begin{tabular}{|c|c|c|c|c|c|}
\hline Source & $\begin{array}{c}\text { Sum of } \\
\text { Squares }\end{array}$ & $\mathbf{D}_{\boldsymbol{f}}$ & $\begin{array}{c}\text { Mean } \\
\text { Square }\end{array}$ & $\begin{array}{c}\boldsymbol{F} \\
\text { Value }\end{array}$ & $\begin{array}{c}\boldsymbol{p} \text {-value } \\
\text { Prob > F }\end{array}$ \\
\hline $\begin{array}{c}\text { Model } \\
\text { significant }\end{array}$ & 2.81 & 3 & 0.94 & 9.44 & 0.0275 \\
\hline A-polymer & 1.12 & 1 & 1.12 & 11.36 & 0.0280 \\
\hline B-plasticizer & 0.67 & 1 & 0.67 & 6.79 & 0.0596 \\
\hline $\begin{array}{c}\text { C-penetration } \\
\text { enhancer }\end{array}$ & 1.01 & 1 & 1.01 & 10.18 & 0.0332 \\
\hline
\end{tabular}
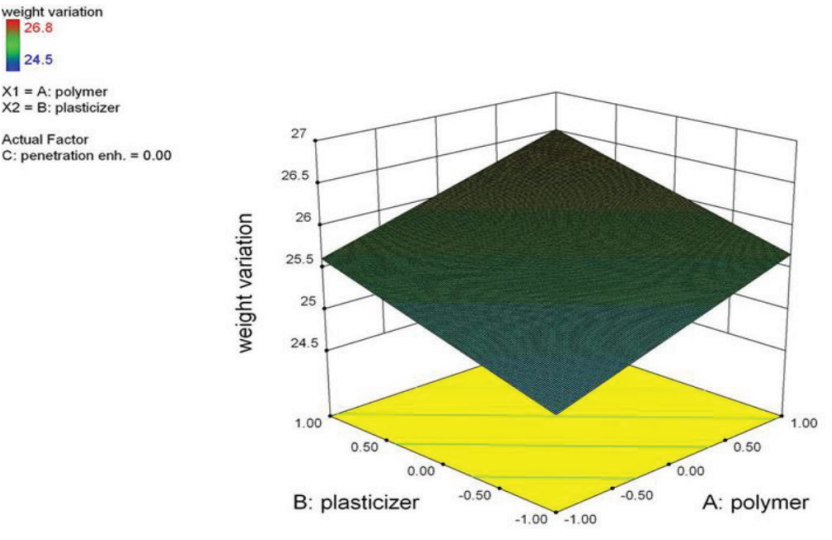

Figure 6: Weight variations of patches as a function of:

a) polymer, b) plasticizer.

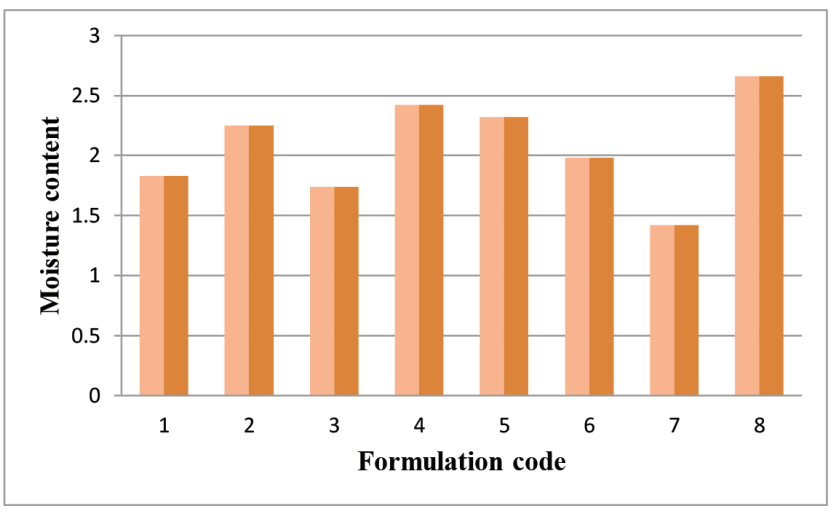

Figure 7: Moisture content of different formulations. 


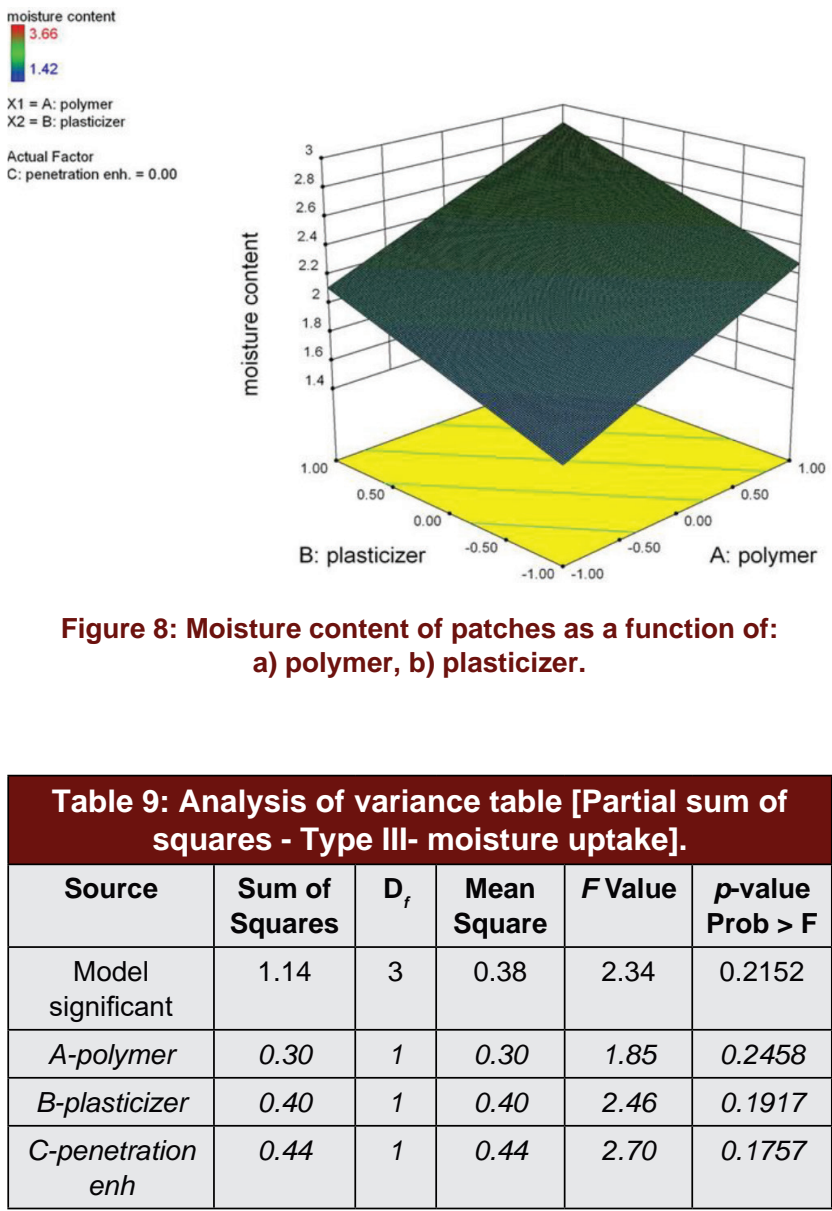

Moisture content $=2.20+0.38 \mathrm{~A}+0.29 \mathrm{~B}+0.36 \mathrm{C}+0.087$ A B +0.11 A C+0.14 BC+0.10 A B C

Where, $\mathrm{A}=$ Polymer, $\mathrm{B}=$ Plasticizer, and $\mathrm{C}=$ Penetration enhancer.

The mathematical models eliciting the effects of the various factors and their interactions over the weight variations of patches were:

Weight variation $=25.65+0.45 \mathrm{~A}+0.42 \mathrm{~B}+0.45 \mathrm{C}-0.025$ A B+0.050 A C-0.025 B C-0.18 A B C

Where, $\mathrm{A}=$ Polymer, $\mathrm{B}=$ Plasticizer, and $\mathrm{C}=$ Penetration enhancer.

The results of percentage moisture uptake of different formulations were given in Table 5. For evaluating the percentage moisture uptake of patches, ANOVA for the selected factorial model was done and details are given in Table 9 and Figure 10. The bar-graph of different formulations vs their percent moisture uptake is given in Figure 9.

The mathematical models eliciting the effects of the various factors and their interactions over percentage moisture uptake of patches were:

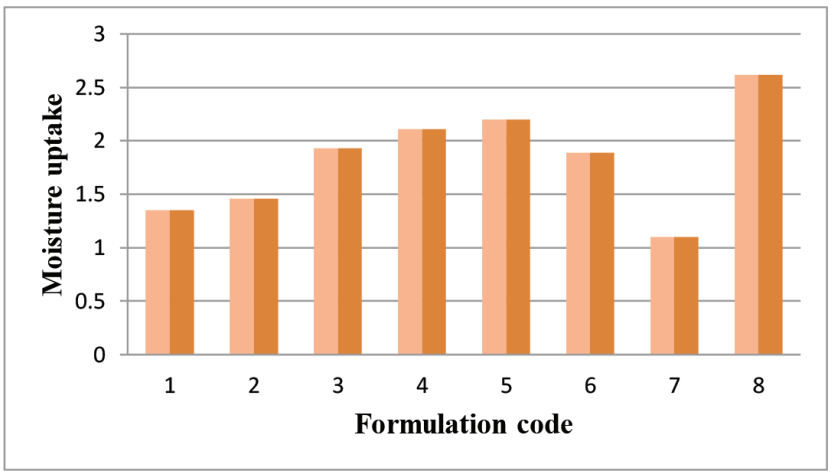

Figure 9: Moisture uptakes of different formulations.
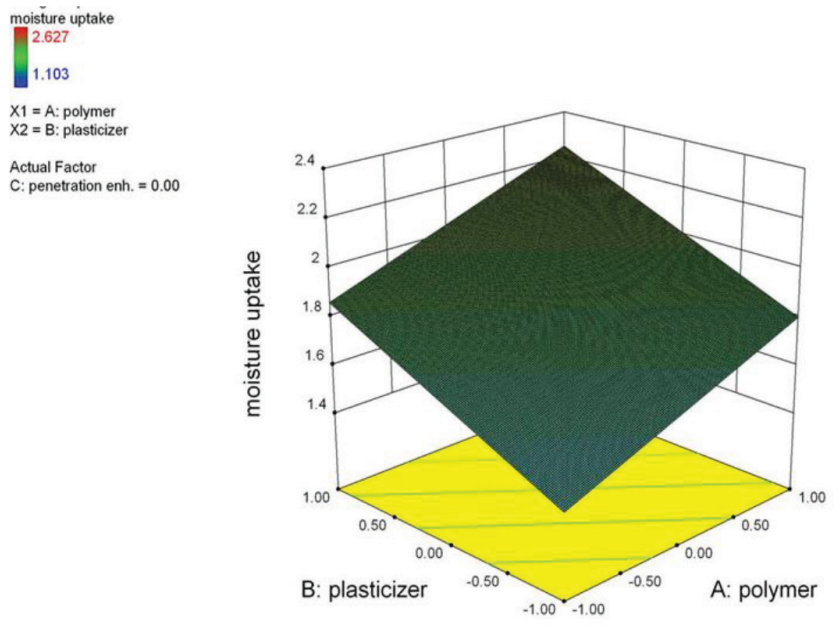

Figure 10: Moisture uptake of patches as a function of: a) polymer, b) plasticizer.

\begin{tabular}{|c|c|c|c|c|c|}
\hline Source & $\begin{array}{l}\text { Sum of } \\
\text { Squares }\end{array}$ & $\mathrm{D}_{f}$ & $\begin{array}{l}\text { Mean } \\
\text { Square }\end{array}$ & $F$ Value & $\begin{array}{c}p \text {-value } \\
\text { Prob }>\text { F }\end{array}$ \\
\hline $\begin{array}{c}\text { Model } \\
\text { significant }\end{array}$ & 71.68 & 3 & 23.89 & 36.32 & 0.0023 \\
\hline A-polymer & 25.63 & 1 & 25.63 & 38.96 & 0.0034 \\
\hline B-plasticizer & 15.24 & 1 & 15.24 & 23.16 & 0.0086 \\
\hline $\begin{array}{c}\text { C-penetration } \\
\text { enh }\end{array}$ & 30.81 & 1 & 30.81 & 46.83 & 0.0024 \\
\hline
\end{tabular}

Moisture uptake $=1.83+0.19 \mathrm{~A}+0.22 \mathrm{~B}+0.23 \mathrm{C}-0.20 \mathrm{~A}$ $\mathrm{B}+0.11 \mathrm{~A} \mathrm{C}+0.12 \mathrm{~B} \mathrm{C}+0.11 \mathrm{~A} \mathrm{~B} \mathrm{C}$

Where, $\mathrm{A}=$ Polymer, $\mathrm{B}=$ Plasticizer, and $\mathrm{C}=$ Penetration enhancer.

Different drug content values of transdermal patches were given in Table 5. For evaluating the drug content of transdermal patches of different formulations, ANOVA for the selected factorial model was done and details are given in Table 10 and Figure 12. The bar-graph of dif- 
ferent formulations vs their percent drug content is given in Figure 11.

The mathematical models eliciting the effects of the various factors and their interactions over drug content of patches were:

Drug content $=91.52+1.79 \mathrm{~A}+1.38 \mathrm{~B}+1.96 \mathrm{C}-0.44 \mathrm{~A}$ B- 0.22 A C- 0.29 B C- 0.018 A B C

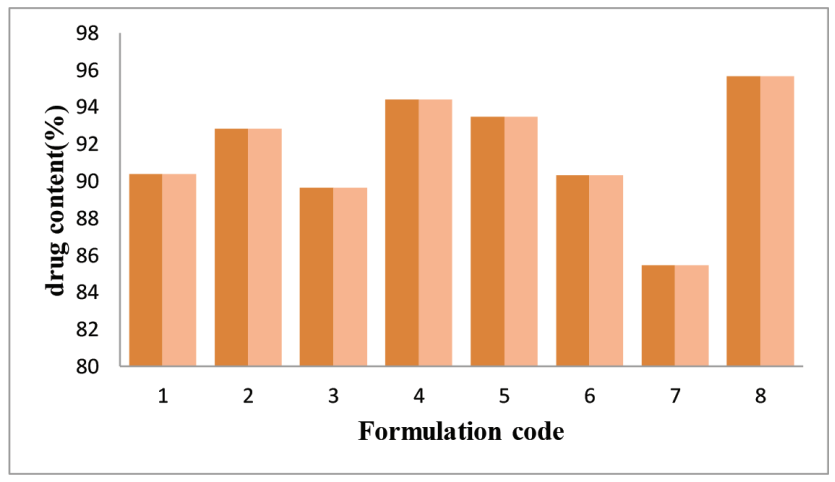

Figure 11: Drug content of different formulations.

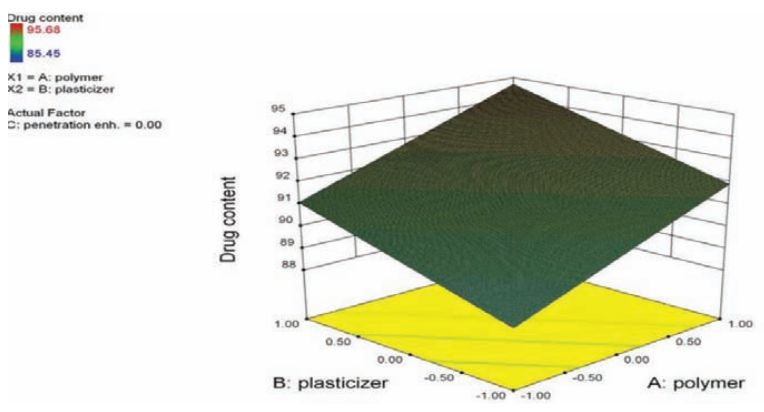

Figure 12: Drug content of patches as a function of: a) polymer, b) plasticizer.
Where, $\mathrm{A}=$ Polymer, $\mathrm{B}=$ Plasticizer, and $\mathrm{C}=$ Penetration enhancer.

The observations of drug permeation across human cadaver skin as the ex-vivo study was given in Table 11 and 12. ANOVA for the selected factorial model was done and details are given in Table 12 and Figure 14. Graph of Drug permeation $\left(\mu \mathrm{g} / \mathrm{cm}^{2}\right)$ of different formulations vrs different formulations is given in Figures 13,15,16.

The mathematical models eliciting the effects of the various factors and their interactions over the thickness of patch were:

Drug permeation $=633.10+15.50 \mathrm{~A}+15.22 \mathrm{~B}+15.08$ C-4.53 A B-4.57 A C+5.14 B C-2.16 A B C.

In the design, the three factors were $A=$ Polymer, $\mathrm{B}=$ Plasticizer, and $\mathrm{C}=$ Penetration enhancer.

\section{DISCUSSION}

Drug compatibility study with all polymers showed no interaction between drug and polymers. The estimated partition coefficient of the drug indicates that the drug has adequate lipophilic characteristics suitable for transdermal patches. Simvastatin containing patches were evaluated for various parameters of transdermal patches including ex-vivo permeation study. Drug content study indicated homogeneous drug distribution in the film and other physicochemical properties were found to be optimum. ${ }^{13,14}$

Formulation F8 has the highest values ofpermeation parameters like flux, amount of drug permeated, and permeability coefficient. Based on all parameters,

\begin{tabular}{|c|c|c|c|c|c|c|c|c|}
\hline \multirow[t]{2}{*}{ Time } & \multicolumn{8}{|c|}{ Drug permeated $\left(\mu \mathrm{g} / \mathrm{cm}^{2}\right)^{*}$} \\
\hline & $F_{1}$ & $\mathbf{F}_{2}$ & $F_{3}$ & $\mathrm{~F}_{4}$ & $\mathbf{F}_{5}$ & $\mathbf{F}_{6}$ & $\mathbf{F}_{7}$ & $F_{8}$ \\
\hline 1 & $58.2 \pm 2.486$ & $50.32 \pm 1.885$ & $52.3 \pm 2.126$ & $55.76 \pm 2.83$ & $56.32 \pm 3.14$ & $53.67 \pm 2.445$ & $48.55 \pm 1.68$ & $57.32 \pm 3.234$ \\
\hline 2 & $93.4 \pm 3.624$ & $91.65 \pm 3.02$ & $91.42 \pm 2.96$ & $96.4 \pm 3.356$ & $102.6 \pm 3.88$ & $93.56 \pm 3.156$ & $88.89 \pm 2.58$ & $103.43 \pm 4.63$ \\
\hline 3 & $120.2 \pm 4.29$ & $118.4 \pm 4.58$ & $124.3 \pm 3.25$ & $112.2 \pm 5.32$ & $131.3 \pm 6.13$ & $125.66 \pm 4.62$ & $127.22 \pm 3.9$ & $136.33 \pm 6.86$ \\
\hline 4 & $151.4 \pm 6.02$ & $165.8 \pm 5.62$ & $148.6 \pm 4.32$ & $158.2 \pm 7.24$ & $165.3 \pm 6.95$ & $158.87 \pm 6.77$ & $150.5 \pm 4.67$ & $168.87 \pm 7.54$ \\
\hline 5 & $178.1 \pm 6.89$ & $204.5 \pm 7.67$ & $187.32 \pm 5.8$ & $198.5 \pm 6.51$ & $192.5 \pm 7.35$ & $189.7 \pm 5.85$ & $175.2 \pm 4.59$ & $192.32 \pm 7.08$ \\
\hline 6 & $210.2 \pm 7.33$ & $246.9 \pm 8.32$ & $239.4 \pm 6.55$ & $243.8 \pm 8.45$ & $239.4 \pm 7.92$ & $224.4 \pm 7.57$ & $206.4 \pm 6.47$ & $229.34 \pm 8.38$ \\
\hline 7 & $240.3 \pm 7.59$ & $275.8 \pm 8.06$ & $268.5 \pm 7.45$ & $274.3 \pm 8.82$ & $293.5 \pm 8.39$ & $268.4 \pm 7.83$ & $242.4 \pm 7.15$ & $264.2 \pm 8.73$ \\
\hline 8 & $275.6 \pm 8.73$ & $304.7 \pm 5.68$ & $296.5 \pm 7.83$ & $299.2 \pm 7.68$ & $322.6 \pm 8.12$ & $285.4 \pm 7.47$ & $272.5 \pm 6.88$ & $294.2 \pm 8.58$ \\
\hline 9 & $301.2 \pm 6.58$ & $340.5 \pm 7.83$ & $330.5 \pm 8.68$ & $334.3 \pm 8.02$ & $360.4 \pm 9.26$ & $311.3 \pm 5.83$ & $306.3 \pm 7.64$ & $322.3 \pm 8.02$ \\
\hline 10 & $320.2 \pm 8.22$ & $365.3 \pm 8.67$ & $364.6 \pm 9.83$ & $365.5 \pm 9.67$ & $381.7 \pm 7.83$ & $345.4 \pm 7.38$ & $331.3 \pm 8.87$ & $348.5 \pm 9.60$ \\
\hline 11 & $355.2 \pm 9.47$ & $396.6 \pm 8.28$ & $390.3 \pm 9.57$ & $394.3 \pm 9.45$ & $416.4 \pm 8.68$ & $384.5 \pm 9.55$ & $361.2 \pm 9.84$ & $385.4 \pm 10.57$ \\
\hline 12 & $396.6 \pm 12.4$ & $410.2 \pm 10.4$ & $402.4 \pm 11.9$ & $408.4 \pm 12.7$ & $428.5 \pm 9.85$ & $408.4 \pm 12.1$ & $392.3 \pm 10.6$ & $432.3 \pm 13.45$ \\
\hline 24 & $610.2 \pm 18.4$ & $645.8 \pm 21.4$ & $618.4 \pm 17.6$ & $640.6 \pm 24.5$ & $664.6 \pm 18.5$ & $630.7 \pm 23.7$ & $585.6 \pm 22.3$ & $672.2 \pm 25.4$ \\
\hline
\end{tabular}

* mean $\pm S . D, n=3$ 
Table 12: Analysis of variance table [partial sum of squares - Type III for drug permeation].

\begin{tabular}{|c|c|c|c|c|c|}
\hline Source & $\begin{array}{c}\text { Sum of } \\
\text { Squares }\end{array}$ & Df & $\begin{array}{c}\text { Mean } \\
\text { Square }\end{array}$ & $\begin{array}{c}\boldsymbol{F} \\
\text { Value }\end{array}$ & $\begin{array}{c}\boldsymbol{p} \text {-value } \\
\text { Prob }>\mathbf{F}\end{array}$ \\
\hline $\begin{array}{c}\text { Model } \\
\text { significant }\end{array}$ & 5593.54 & 3 & 1864.51 & 12.85 & 0.0160 \\
\hline A-polymer & 1922.31 & 1 & 1922.31 & 13.25 & 0.0220 \\
\hline B-plasticizer & 1852.88 & 1 & 1852.88 & 12.77 & 0.0233 \\
\hline $\begin{array}{c}\text { C-penetration } \\
\text { enhancer }\end{array}$ & 1818.35 & 1 & 1818.35 & 12.53 & 0.0240 \\
\hline
\end{tabular}

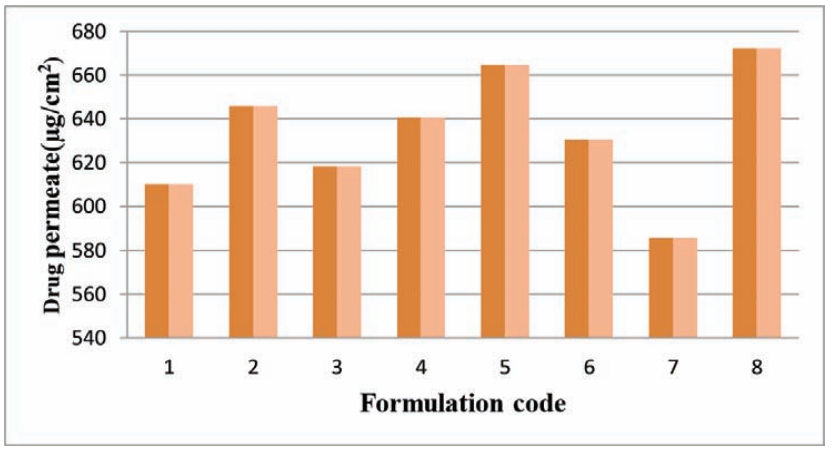

Figure 13: Drug permeation of different formulations.

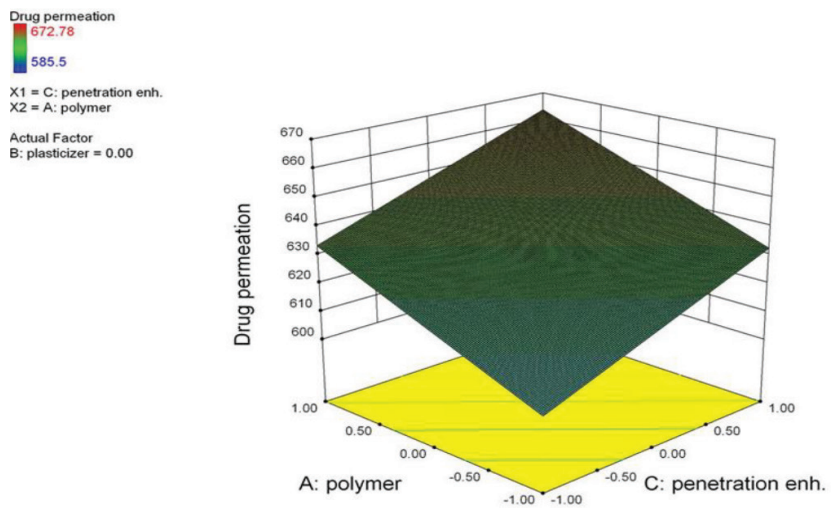

Figure 14: Drug permeation of patches as a function of: a) polymer, b) penetration enhancer.

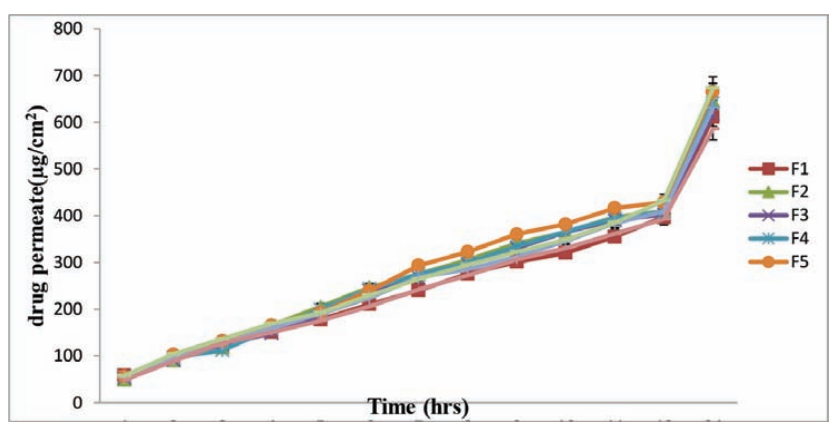

Figure 15: Amount of drug permeated from different patches.

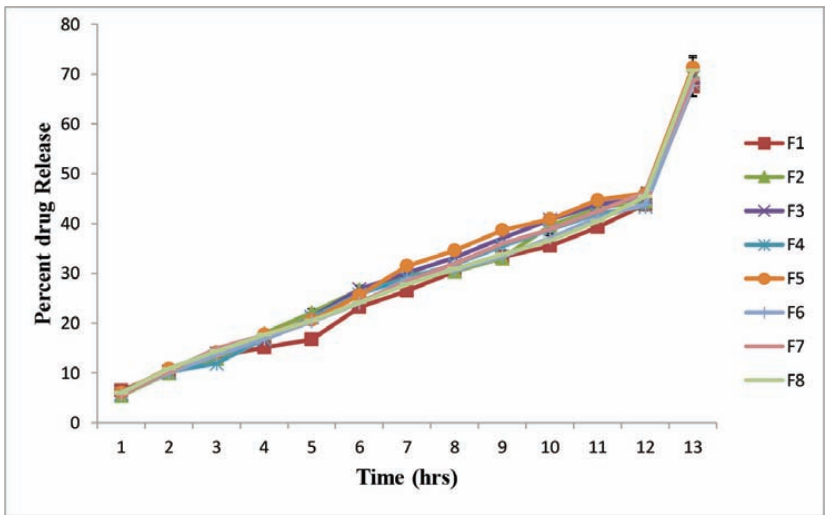

Figure 16: Percent drug permeation from different patch formulations.

formulation $\mathrm{F} 8$ was considered as the best formulation. The films were subjected to stability studies at $45^{\circ} \mathrm{C}$ and $75 \% \mathrm{RH}$ for 45 days and were found stable with respect to their physicochemical parameters, drug permeation, and flux value.

\section{CONCLUSION}

Simvastatin was found compatible with all polymers and excipients used for the formulations. The estimated partition coefficient of the drug indicates that the drug possesses sufficient lipophilicity which meets the requirements of a transdermal patch. It may be a promising delivery system for the treatment of primary hypercholesterolemia.

\section{ACKNOWLEDGEMENT}

Authors are thankful to the Centre for Advanced Research in Pharmaceutical Sciences, Shobhit Institute of Engineering and Technology, a Deemed to be University for giving an opportunity to work with their facilities to complete the work. The authors are thankful to Cadila Pharma. Ltd, Gujarat, and Evonik Industries, Germany for proving gift samples.

\section{CONFLICT OF INTEREST}

The authors declare no conflict of interest.

\section{ABBREVIATIONS}

DMSO: Dimethyl Sulphoxide; RH: Relative Humidity; h: Hour; $\mu \mathrm{m}$ : Micrometer; w/v: weight/volume; EDTA: Ethylene Diamine Tetraacetic Acid; SD: Standard Deviation; Df: Degree of freedom. 


\section{REFERENCES}

1. Prausnitz MR, Mitragotri S, Langer R. Current status and future potential of transdermal drug delivery. Nat Rev Drug Discov. 2004;3(2):115-24. doi: 10.1038/nrd1304, PMID 15040576.

2. Ansel HC, Loyd AV, Popovich NG. Pharmaceutical dosage forms and drug delivery systems. 7th ed. Philadelphia: Lippincott Williams \& Wilkins; 2011.

3. Rao PR, Diwan PV. Permeability studies of cellulose acetate free films for transdermal use: influence of plasticizers. Pharm Acta Helv. 1997;72(1):47-51. doi: 10.1016/s0031-6865(96)00060-x, PMID 9063088.

4. El-Gendy NA, Sabry NA, El-Attar M, Omar E, Mahmoud M. Transdermal delivery of salbutamol sulphate: formulation and evaluation. Pharm Dev Technol. 2009;14(2):216-25. doi: 10.1080/10837450802572383, PMID 19519194.

5. Shinde AJ, Garala KC, More H. Development and characterization of transdermal therapeutics system of tramadol hydrochloride. Asian J Pharm. 2008;2(4):265-9. doi: 10.4103/0973-8398.45044.

6. Zhang $\mathrm{Y}$, Cun $\mathrm{D}$, Kong $\mathrm{X}$, Fang $\mathrm{L}$. Design and evaluation of a novel transdermal patch containing diclofenac and teriflunomide for rheumatoid arthritis therapy. Asian Journal of Pharmaceutical Sciences. 2014;9(5):251-9. doi: 10.1016/j.ajps.2014.07.007.

7. Chourasia S, Shukla T, Dangi S, Upmanyu N, Jain N. Formulation and evaluation of matrix transdermal patches of meloxicam. J Drug Delivery Ther. 2019;9(1-s):209-13. doi: 10.22270/jddt.v9i1-s.2326.
8. Mundargi RC, Patil SA, Agnihotri SA, Aminabhavi TM. Evaluation and controlled release characteristics of modified xanthan films for transdermal delivery of atenolol. Drug Dev Ind Pharm. 2007;33(1):79-90. doi: 10.1080/03639040600975030, PMID 17192254.

9. Sood A, Panchagnula R. Role of dissolution studies in controlled release drug delivery system. STP Pharm Sci. 1999;9:157-68.

10. Tymes NW, Shah VP, Skelly JP. In vitro release profile of estradiol transdermal therapeutic systems. J Pharm Sci. 1990;79(7):601-2. doi: 10.1002/ jps.2600790711, PMID 2398467.

11. Murthy SN, Hiremath SRR. Physical and chemical permeation enhancers in transdermal delivery of terbutaline sulphate. AAPS PharmSciTech. 2001;2(1):E-TN1. doi: 10.1208/pt0201_tn1, PMID 14727885.

12. Panchagnula R, Bokalial R, Sharma P, Khandavilli S. Transdermal delivery of naloxone: skin permeation, pharmacokinetic, irritancy and stability studies. Int J Pharm. 2005;293(1-2):213-23. doi: 10.1016/j.ijpharm.2005.01.004, PMID 15778059.

13. Tanwar H, Sachdeva R. Transdermal drug delivery system: a review. IndJ Pharm Sci Res.2016;7(6):2274-90.

14. Dwivedi S, Tawar P, Gehlot S, Dubey R. Development and Evaluation of transdermal Patches of cinnarizine for the Treatment of allergy.Chroni. Pharm Sci. 2018;2(6):692-701.

\section{PICTORIAL ABSTRACT}

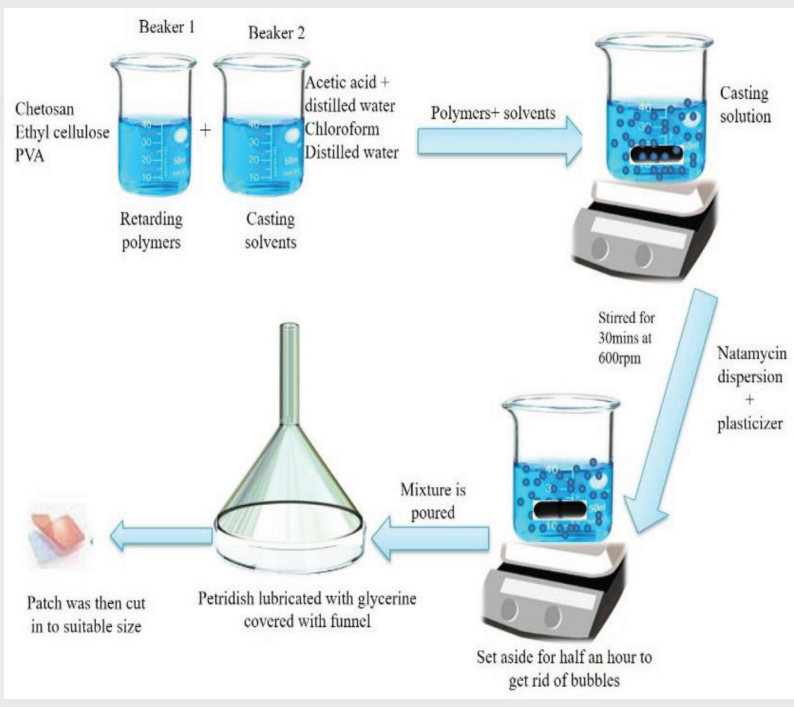

\section{SUMMARY}

- Simvastatin-containing patches were evaluated for weight variation, thickness, folding endurance, percentage moisture uptake, percentage moisture content, drug content, and ex-vivo permeation study. Drug content study indicated homogeneous drug distribution in the film and other physicochemical properties were found to be optimum.

- The permeation parameters like flux, amount of drug permeated, and permeability coefficient were found highest for formulation F8, based on all parameters, formulation F8 was considered as the best formulation. The films were subjected to stability studies at $45^{\circ} \mathrm{C}$ and $75 \% \mathrm{RH}$ for 45 days and were found stable concerning their physicochemical parameters, drug permeation, and flux value.

\section{About Authors}

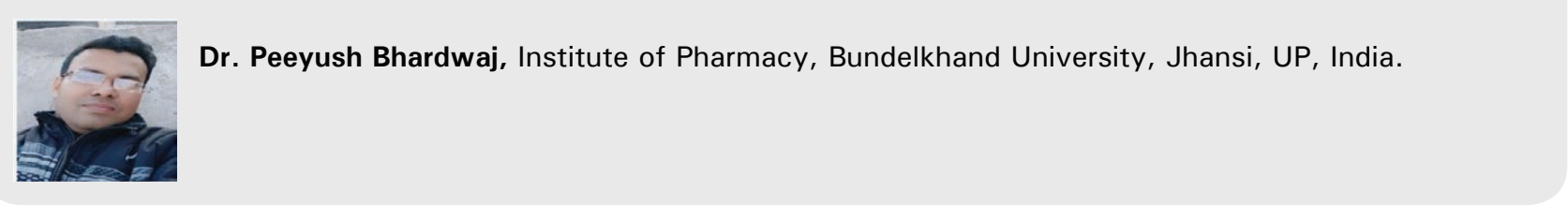

Cite this article: Mishra SK, Kumar R, Patil PR, Gupta R, Mahor A, Bhardwaj P. Preparation and Characterization of Transdermal Therapeutic System Containing Simvastatin: A Statistical Study. Indian J of Pharmaceutical Education and Research. 2022;56(1):112-20. 